\title{
A thermogravimetric study of thermal dehydration of copper hexacyanoferrate by means of model-free kinetic analysis
}

\author{
Ida E. Åkerblom ${ }^{1} \cdot$ Dickson O. Ojwang $^{1}$ ([) $\cdot$ Jekabs Grins $^{1} \cdot$ Gunnar Svensson $^{1}$ (1)
}

Received: 4 October 2016/Accepted: 6 March 2017/Published online: 16 March 2017

(c) The Author(s) 2017. This article is an open access publication

\begin{abstract}
The kinetics of thermal dehydration of $\mathrm{K}_{2 \times / 3} \mathrm{Cu}$ $\left[\mathrm{Fe}(\mathrm{CN})_{6}\right]_{2 / 3} \cdot n \mathrm{H}_{2} \mathrm{O}$ was studied using thermogravimetry for $x=0.0$ and 1.0. Data from both non-isothermal and isothermal measurements were used for model-free kinetic analysis by the Friedman and KAS methods. The water content was determined to be $n=2.9-3.9$, plus an additional $\sim 10 \%$ of water, likely surface adsorbed, that leaves very fast when samples are exposed to a dry atmosphere. The determined average activation energy for $0.2 \leq \alpha \leq 0.8$ is $56 \mathrm{~kJ} \mathrm{~mol}^{-1}$. The dehydration is adequately described as a diffusion-controlled single-step reaction following the $\mathrm{D} 3$ Jander model. The determined dehydration enthalpy is $11 \mathrm{~kJ}\left(\mathrm{~mol} \mathrm{H}_{2} \mathrm{O}\right)^{-1}$ for $x=0.0$ and $27 \mathrm{~kJ}\left(\mathrm{~mol} \mathrm{H}_{2} \mathrm{O}\right)^{-1}$ for $x=1.0$, relative to that of water. The increase with increasing $x$ is evidence that the $\mathrm{H}_{2} \mathrm{O}$ molecules form bonds to the incorporated $\mathrm{K}^{+}$ions.
\end{abstract}

Keywords Copper hexacyanoferrate $\cdot$ Thermal dehydration - Thermogravimetry $\cdot$ Kinetic analysis . Activation energy $\cdot$ Dehydration enthalpy

Electronic supplementary material The online version of this article (doi:10.1007/s10973-017-6280-x) contains supplementary material, which is available to authorized users.

\section{Gunnar Svensson}

gunnar.svensson@mmk.su.se

1 Department of Materials and Environmental Chemistry, Arrhenius Laboratory, Stockholm University, SE-10691 Stockholm, Sweden

\section{Introduction}

Rechargeable battery systems manufactured from low-cost materials are needed to support current intermittent power sources, e.g. the sun and wind [1]. Water-based systems with Prussian blue analogues (PBAs), e.g. copper hexacyanoferrate $(\mathrm{CuHCF})$, as electrodes exhibit a number of merits; they can be synthesized in large quantities from cheap precursors and show long cycle lives, fast kinetics, high power operations, and good energy efficiencies [2]. There has been a burgeoning interest in Prussian blue (PB) and PBA compounds in the last decades for other applications as well; hydrogen storage [3], electrocatalysis [4], and charge storage [5], are a few examples from a large variety of fields. Their physical and chemical properties have been extensively studied by many experimental methods, e.g. X-ray diffraction $[6,7]$, neutron diffraction [8,9], magnetic susceptibility and infrared [10], EXAFS [11], and Mössbauer spectroscopy [12] among others.

$\mathrm{PB}$ compounds are traditionally distinguished as soluble, i.e. alkali-rich, with formula $\mathrm{AFe}^{\mathrm{III}}\left[\mathrm{Fe}^{\mathrm{II}}(\mathrm{CN})_{6}\right] \cdot 1-5 \mathrm{H}_{2} \mathrm{O}$, where $\mathrm{A}$ is an alkali metal cation or $\mathrm{NH}_{4}^{+}$, or insoluble, i.e. alkali-free, with formula $\mathrm{Fe}^{\mathrm{III}}\left[\mathrm{Fe}^{\mathrm{II}}(\mathrm{CN})_{6}\right]_{3 / 4} \cdot 3.5-4 \mathrm{H}_{2} \mathrm{O}$. The two terms soluble and insoluble refer to the ease of peptization rather than true solubility, as both compounds are highly insoluble in water $[13,14]$. PBAs have a general formula $\mathrm{A}_{\mathrm{x}} \mathrm{M}\left[\mathrm{M}^{\prime}(\mathrm{CN})_{6}\right]_{\mathrm{z}} \cdot n \mathrm{H}_{2} \mathrm{O}$, where $\mathrm{M}$ and $\mathrm{M}^{\prime}$ are transition metal ions, $\mathrm{A}$ is a monovalent cation, and $z \leq 1$. The crystal structure of PB was first analysed by Keggin and Miles using X-ray powder diffraction data [6]. The currently accepted structure model for alkali-free PB was presented in the 1970s by Buser et al. [7], derived from single-crystal X-ray diffraction data. Most PBA structures are isotypic with that of $\mathrm{PB}$ and crystallize in the cubic 
space group $F m \overline{3} m$, albeit structures with lower symmetries do exist $[15,16]$.

A cubic $F m \overline{3} m$ PBA crystal structure has a cyanidebridged perovskite-type framework of $-\mathrm{NC}-\mathrm{M}^{\prime}-\mathrm{CN}-\mathrm{M}-$ $\mathrm{NC}$ - linear linkages with a proportion $z$ of $\mathrm{M}^{\prime}(\mathrm{CN})_{6}$ sites randomly vacant [17]. The coordination sphere of $\mathrm{M}$ ions is completed by coordinated water molecules, see Fig. 1 . In addition, zeolitic water molecules/and or alkali ions occupy the voids/cavities in the $\mathrm{M}^{\prime}-\mathrm{CN}-\mathrm{M}$ framework [9]. For alkali-free $\mathrm{PB}$, the locations of the two kinds of water molecules have been determined from neutron diffraction data $[8,9]$. Three distinct sites have been identified; (1) for zeolitic water, the $8 c$ site $(1 / 4,1 / 4,1 / 4)$ and a $32 f$ site $(x, x, x)$, at the centre and around the centre of the cavity, respectively, and (2) for coordinated water, a $24 e$ site $(x, 0,0)$ close to the position of missing $\mathrm{C} / \mathrm{N}$ atoms. The maximum number of water molecules is per unit cell for $x=0.0$ and $z=2 / 3$ ideally 16,8 zeolitic, and 8 coordinated [9].

Despite many investigations on the synthesis, structure characterization, properties, and applications, little research has been carried out to understand the kinetics of thermal dehydration processes. A literature survey revealed only one study on the activation energy of dehydration in PBAs; for $\mathrm{M}\left[\mathrm{Co}^{\mathrm{III}}(\mathrm{CN})_{6}\right]_{2 / 3} \cdot n \mathrm{H}_{2} \mathrm{O}$ with $\mathrm{M}=\mathrm{Ni}, \mathrm{Zn}$ by modulated TG [18]. Moreover, the total water content of PBAs is often ill-defined, as it is sensitive to the route of synthesis and ambient conditions [17, 19]. In this study, we have investigated the characteristics and kinetics of the thermal dehydration of the two end compositions of $\mathrm{K}_{2 \times / 3} \mathrm{Cu}\left[\mathrm{Fe}(\mathrm{CN})_{6}\right]_{2 / 3} \cdot n \mathrm{H}_{2} \mathrm{O}$ with nominally $x=0.0$ and $x=1.0$, using model-free kinetic analysis, as well as determined the degree of hydration as a function of $x$. The analyses herein are based on TG and supplemented by evolved gas analysis (EGA) by mass spectrometry (MS) and DSC.

\section{Experimental}

\section{Synthesis}

The $\mathrm{Cu}^{\mathrm{II}}\left[\mathrm{Fe}^{\mathrm{III}}(\mathrm{CN})_{6}\right]_{2 / 3} \cdot n \mathrm{H}_{2} \mathrm{O}$ compound was prepared by precipitation at room temperature. Aqueous precursors of $\mathrm{Cu}\left(\mathrm{NO}_{3}\right)_{2} \quad(0.08 \mathrm{M}, \quad 50 \mathrm{~mL} ; \quad$ Sigma-Aldrich $)$ and $\mathrm{K}_{3} \mathrm{Fe}(\mathrm{CN})_{6}(0.04 \mathrm{M}, 50 \mathrm{~mL}$; Sigma-Aldrich) were simultaneously added to $25 \mathrm{~mL}$ of water during constant stirring. The precipitation can be formulated as

$$
\begin{aligned}
\mathrm{Cu}^{\mathrm{II}}(\mathrm{aq})+2 / 3\left[\mathrm{Fe}^{\mathrm{III}}(\mathrm{CN})_{6}\right]^{3-}(\mathrm{aq}) \\
\leftrightarrow \mathrm{Cu}^{\mathrm{II}}\left[\mathrm{Fe}^{\mathrm{III}}(\mathrm{CN})_{6}\right]_{2 / 3} \cdot n \mathrm{H}_{2} \mathrm{O}(\mathrm{s})
\end{aligned}
$$

A series of $\mathrm{K}_{2 \mathrm{x} / 3} \mathrm{Cu}^{\mathrm{II}}\left[\mathrm{Fe}_{\mathrm{x}}^{\mathrm{II}} \mathrm{Fe}_{1-\mathrm{x}}^{\mathrm{III}}(\mathrm{CN})_{6}\right]_{2 / 3} \cdot n \mathrm{H}_{2} \mathrm{O}$ samples with nominally $0.0 \leq x \leq 1.0$ and $\Delta x=0.2$ were synthesized by reducing $\mathrm{Fe}^{\mathrm{III}}$ in $\mathrm{Cu}^{\mathrm{II}}\left[\mathrm{Fe}^{\mathrm{III}}(\mathrm{CN})_{6}\right]_{2 / 3} \cdot n \mathrm{H}_{2} \mathrm{O}$ (s) with aqueous $\mathrm{K}_{2} \mathrm{~S}_{2} \mathrm{O}_{3}$. The products were washed, freeze-dried, and ground to fine powders. Elemental analysis of the powder samples using inductively coupled plasma (ICP) and combustion analysis were performed by Medac Ltd., UK. The K contents for the $x=0.0$ and 1.0 samples were determined by ICP to be $x=0.09$ (5) and 0.92 (5), respectively. For $x=0.0$, the presence of $\mathrm{K}$ originates from the precursor $\mathrm{K}_{3} \mathrm{Fe}(\mathrm{CN})_{6}$. Detailed description of the synthesis procedure and sample preparation is reported elsewhere [19]. Sample morphology and particle size were studied with a scanning electron microscope (SEM, JEOL JSM-7401F) operated at an accelerating voltage of $2 \mathrm{kV}$. A Panalytical PRO MPD powder $\mathrm{X}$-ray diffractometer, using $\mathrm{Cu} \mathrm{K} \alpha_{1}$ radiation, was used to identify end products in TG runs.

\section{TG-DSC and TG-MS}

TG-DSC measurements were recorded with a Netzsch F3 449 Jupiter STA (JT = Jupiter thermobalance), and TGMS measurements with a TA Instruments Discovery
Fig. 1 Illustration of the cubic $F m \overline{3} m$ crystal structure of a PBA with (left) zeolitic water (pink) distributed over a fraction of $8 c$ and $32 f$ sites in the cavities, and (right) coordinated water (pink) completing the coordination sphere of adjacent $\mathrm{M}$ metals (green) in case of $\mathrm{M}^{\prime}(\mathrm{CN})_{6}$ vacancies. $R e d$ and green atoms $=\mathrm{M}$ and $\mathrm{M}^{\prime}$ transition metals, and black and blue atoms $=\mathrm{C}$ and $\mathrm{N}$ atoms, respectively. (Color figure online)
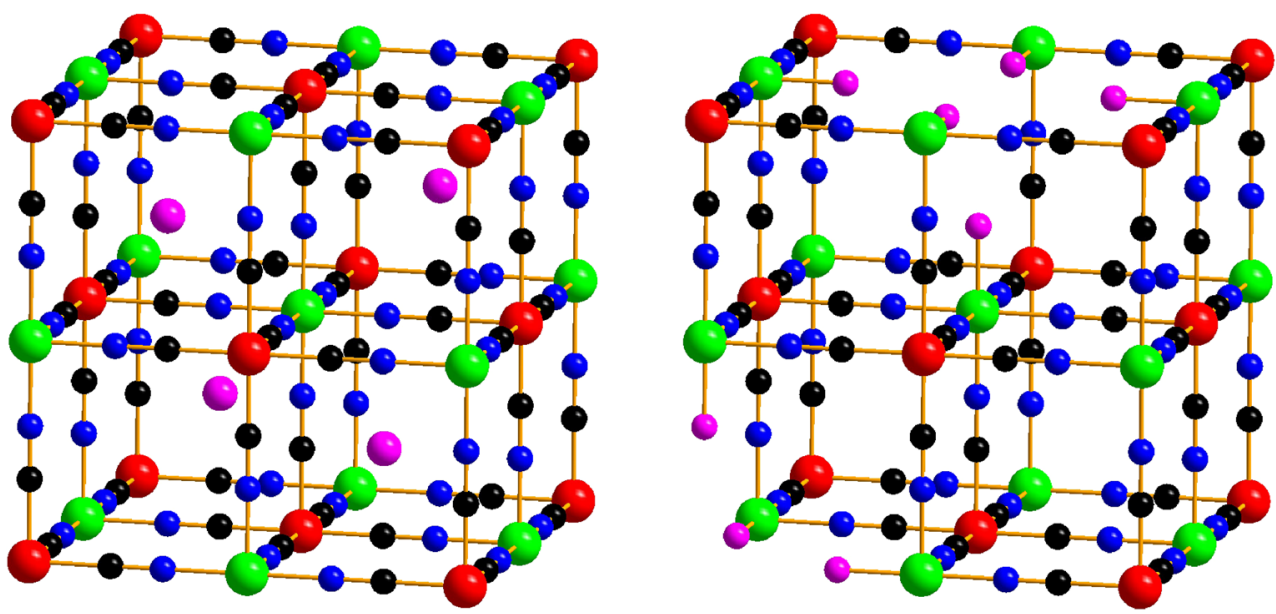
thermobalance $(\mathrm{DT}=$ Discovery thermobalance) and a connected Pfeiffer Thermostar mass spectrometer. All runs were made with samples placed in alumina cups (JT) or pans (DT), as Pt containers were found to react with the samples during decomposition.

Non-isothermal TG measurements were made with heating rates of $2,5,10$, and $20{ }^{\circ} \mathrm{C} \mathrm{min}^{-1}$ for samples with $x=0.0$ and $x=1.0$ up to $900{ }^{\circ} \mathrm{C}$ in air $\left(50 \mathrm{~mL} \mathrm{~min}{ }^{-1}\right)$, using sample amounts of $\sim 10 \mathrm{mg}$ and, to ensure accuracy, both thermobalances. All samples were equilibrated with room atmosphere prior to the runs. In addition, corresponding runs were made also in $\mathrm{N}_{2}$ gas atmosphere for $x=0.0$ using the DT. Isothermal measurements were performed for samples $x=0.0$ and $x=1.0$ at seven different temperatures between 40 and $150{ }^{\circ} \mathrm{C}$ with the DT. The effect of sample amount on obtained TG curves was investigated using amounts of 3-18 $\mathrm{mg}$ with the JT. One additional run was also made with an $11 \mathrm{mg}$ sample in a cup with a lid. Water contents were determined for nominal $x$ values 0.0 , $0.2,0.4,0.6,0.8$, and 1.0 from TG runs in air and at heating rates of $10{ }^{\circ} \mathrm{C} \mathrm{min}{ }^{-1}$. DSC and TG data were recorded simultaneously in runs using the JT. MS curves were recorded for samples $x=0.0$ and $x=1.0$ for TG runs in air at a heating rate of $10{ }^{\circ} \mathrm{C} \mathrm{min}^{-1}$ using the DT.

\section{Kinetic calculations}

The rate of the dehydration, $\mathrm{d} \alpha / \mathrm{d} t$, is described by the general kinetic rate equation

$\frac{\mathrm{d} \alpha}{\mathrm{d} t}=k(T) \cdot f(\alpha)$

where $t$ is time, $T$ the absolute temperature, and $k$ the rate constant. The conversion, $0 \leq \alpha \leq 1$, is a measure of the extent of the reaction and determined from the mass loss data. Equation (2) describes the rate as a linear function of the temperature-dependent rate constant $k(T)$ and the conversion-dependent reaction model $f(\alpha)$ [20]. The reaction model is classified according to mechanistic assumptions like nucleation, diffusion, or reaction order [21] and varies for different type of processes. The mathematical expressions for several of the most commonly occurring reaction models are given in Ref. [21]. The rate constant is generally expressed by the Arrhenius equation

$k(T)=A \cdot \exp \left(\frac{-E_{\mathrm{a}}}{R T}\right)$

with $A$ being the pre-exponential factor (time ${ }^{-1}$ ), presumed usually to be temperature independent, $E_{\mathrm{a}}$ the activation energy $\left(\mathrm{kJ} \mathrm{mol}^{-1}\right)$, and $R$ the gas constant $\left(8.314 \mathrm{~J} \mathrm{~K}^{-1}\right.$ $\mathrm{mol}^{-1}$ ). Substituting the Arrhenius expression into Eq. (2) gives the standard kinetic equation under isothermal or non-isothermal conditions

$\frac{\mathrm{d} \alpha}{\mathrm{d} t}=\beta \frac{\mathrm{d} \alpha}{\mathrm{d} T}=A \cdot \exp \left(\frac{-E_{\mathrm{a}}}{R T}\right) \cdot f(\alpha)$

with $\beta$ being the heating rate $\left(\mathrm{K}_{\text {time }}{ }^{-1}\right)$. An adequate kinetic description of a reaction process is typically in the form of the kinetic triplet of the two Arrhenius parameters and the reaction model. Procedures for determining the reaction mechanism usually involve fitting experimental data to different reaction models, and choosing the model with the best fit to be the one that best describes the kinetics of the process. A problem with model-fitting methods is that they often yield results where several models show a good fit, but which have significantly different values of $E_{\mathrm{a}}$ and $A$. Furthermore, these model-fitting methods yield a single kinetic triplet for the entire process, thus assuming that the reaction is a single-step process. Consequently, they do not allow for possible changes in the rate limiting step and are not able to account for multiple reaction steps. For these reasons, we have in this study instead used model-free or isoconversional methods, as recommended by the ICTAC Kinetics Committee [22].

\section{Model-free kinetics}

Isoconversional methods rest on the assumption that the reaction models are independent of temperature and can be considered constant at fixed values of conversion. As isoconversional kinetic analyses are carried out over a set of measurements at specific values of $\alpha$, the reaction rate will be a function of temperature only [23]. Isoconversional methods are able to separate the temperature and conversion-dependent expressions in Eq. (2) and provide modelfree estimations of the values of $E_{\mathrm{a}}$ and $A$ at different $\alpha$-values, $E_{\alpha}$ and $A_{\alpha}$, respectively. Constant values of $E_{\mathrm{a}}$ can be expected in the case of single-step processes, whereas variations in contributions from several steps to the net reaction rate in multi-step processes would result in a variation of $E_{\mathrm{a}}$ with $\alpha$. The model-free methods can be divided into two separate groups, differential or integral methods.

Friedman method The most commonly used differential isoconversional method is the Friedman method [24], applicable to both isothermal and non-isothermal data, according to which:

$\ln \left[\beta\left(\frac{\mathrm{d} \alpha}{\mathrm{d} T}\right)\right]_{\alpha, \mathrm{i}}=\ln \left[A_{\alpha} f(\alpha)\right]-\frac{E_{\alpha}}{R T_{\alpha, \mathrm{i}}}$

The dependence of $\ln [\beta(\mathrm{d} \alpha / \mathrm{d} t)]_{\alpha, \mathrm{i}}$ over $1 / T_{\alpha, \mathrm{i}}$ is linear, as the function $f(\alpha)$ is assumed constant at each specific value 
of conversion $\alpha$, for all temperature programs $i$. By plotting the dependence, for different heating rates and at a fixed degree of $\alpha$, a straight line with slope $-E_{\alpha} / R T$ is obtained, from which $E_{\alpha}$ can be estimated.

Kissinger-Akahira-Sunose method There are various integral methods that originate from approximations of the integrated non-isothermal form of Eq. (4) [25]

$g(\alpha)=\frac{A}{\beta} \int_{0}^{T} \exp \left(\frac{-E_{\mathrm{a}}}{R T}\right) \mathrm{d} T$

with $g(\alpha)=\int_{0}^{\alpha} f(\alpha)^{-1} \mathrm{~d} \alpha$ being the integral expression of the reaction mechanism. The approximation by Coats and Redfern [25] give rise to the equation applied by the Kissinger-Akahira-Sunose method (KAS) [26, 27].

$\ln \left(\frac{\beta}{T^{2}}\right)=\ln \frac{A_{\alpha} \cdot R}{E_{\alpha} \cdot g(\alpha)}-\frac{E_{\alpha}}{R T}$

Again, at a constant $\alpha$, the apparent $E_{\alpha}$ can be estimated from the slope of the straight line obtained by plotting $\ln \left(\beta / T^{2}\right)$ versus $1 / T$.

Estimation of the pre-exponential factor and reaction model $g(\alpha)$ As the pre-exponential factor is grouped together with $f(\alpha)$ and $g(\alpha)$ in the intercept of the isoconversional plots, see Eqs. (5) and (7), the methods cannot be used to estimate $A$ without making assumptions about the model. A model-free evaluation [28] of the pre-exponential factor can be accomplished by the use of the so-called compensation effect, which is observed when several models are fitted to a single heating run. Different pairs of the Arrhenius parameters, $A_{\mathrm{j}}$ and $E_{\mathrm{j}}$, are obtained by substituting expressions of $g(\alpha)$ for different reaction models $j$ and fitting them to experimental data according to

$\ln \left(\frac{g(\alpha)}{T^{2}}\right)=\ln \left[\frac{A_{\mathrm{j}} R}{\beta E_{\mathrm{j}}}\right]-\frac{E_{\mathrm{j}}}{R T}$

A correlation between the obtained parameters is observed, obeying a linear relationship called the compensation effect.

$\ln A_{\mathrm{j}}=c+d \cdot E_{\mathrm{j}}$

where $c$ and $d$ are compensation effect constants. By plotting the parameters $\ln A_{\mathrm{j}}$ and $E_{\mathrm{j}}$, for a single heating run and different models, the compensation effect constants can be determined. An estimated value of the $E_{\alpha}$ from an isoconversional method can then be substituted into Eq. (9) and $\ln A_{\alpha}$ solved for as

$\ln A_{\alpha}=c+d \cdot E_{\alpha}$

Once the Arrhenius parameters are estimated, the reaction model can be reconstructed numerically by inserting them into

$g(\alpha)=\frac{A_{\alpha} \cdot R \cdot \exp \left(-\frac{E_{\alpha}}{R T}\right) \cdot T^{2}}{\beta \cdot E_{\alpha}}$

\section{Predictions}

Once the kinetic triplet has been solved for, it can be used to predict the reaction behaviour under other temperature conditions, e.g. curves recorded in isothermal measurements can be compared with prediction curves calculated as

$t=\frac{g(\alpha)}{A \cdot \exp \left(-\frac{E_{\mathrm{a}}}{R T}\right)}$

An estimation of the thermal stability of a material can thus be estimated by predicting the time it takes to reach a certain extent of the reaction at a specific temperature. The predictions also work as verification that the obtained results are able to adequately describe the reaction behaviour.

\section{Results and discussion}

\section{Size and morphology of samples}

A SEM picture of the as-synthesized $x=0.0$ sample is shown in Fig. 2. The sample is composed of nanoparticles of similar size, $\sim 30-100 \mathrm{~nm}$, which aggregate to form a porous network. A similar morphology was observed for all $x$. Individual larger and denser aggregates could, however, be observed with an optical microscope, amounting to

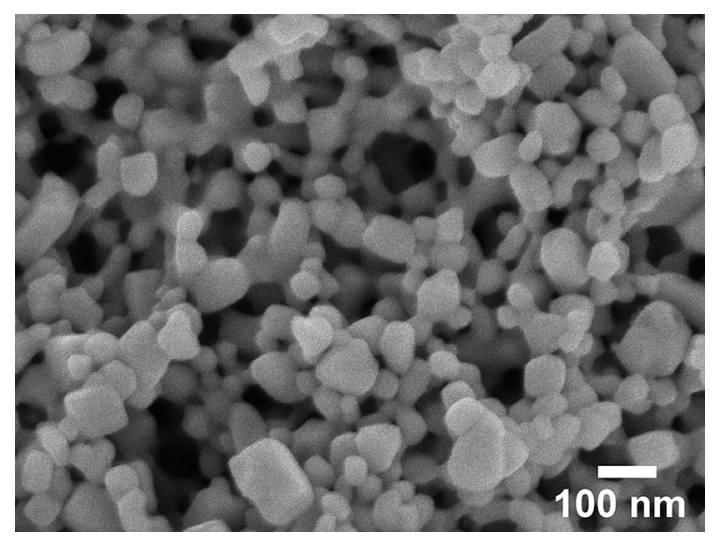

Fig. 2 Secondary electron SEM image of the as-synthesized $x=0.0$ sample 
an estimated fraction of $\sim 5 \%$. In order to eliminate the large aggregates, the samples were gently ground before the TG runs.

\section{TG and evolved EGA measurements}

Figure 3 shows the TG and MS curves for $x=1.0$ in air at a heating rate of $10{ }^{\circ} \mathrm{C} \mathrm{min}-1$. TG-MS curves for $x=0.0$ in $\mathrm{N}_{2}$ and for $x=1.0 \mathrm{in}$ air and $\mathrm{N}_{2}$ are given in the SI. The curves are similar to those recorded in $\mathrm{N}_{2}$ by Pasta et al. [2]. A well-defined first mass loss step associated with the removal of water is observed in the temperature region up to $\sim 130{ }^{\circ} \mathrm{C}$. The strong MS signals from $m / z 18\left(\mathrm{H}_{2} \mathrm{O}\right)$ and $\mathrm{m} / \mathrm{z}, 17(\mathrm{OH})$ confirm that the step is due to loss of water, corresponding to $\sim 21 \%$ of the total mass, and there is no MS signal from $\mathrm{H}_{2} \mathrm{O}$ above $130{ }^{\circ} \mathrm{C}$. This was also found to be the case for $x=0.0$. Only the first mass loss step was therefore considered for kinetic analysis of the dehydration and determination of water content. The dehydration of CuHCF has been previously found to be reversible [19].

The $\mathrm{MS} \mathrm{H}_{2} \mathrm{O}$ signal suggests, however, that the dehydration step consists of two strongly overlapping processes, of similar magnitude, which can be ascribed to loss of zeolitic and coordinated water, respectively. Two close dehydration steps could, however, only be discerned for $x=1.0$, and not for $x=0.0$. For $x=1.0$ they were indicated also by differential TG curves and DSC curves, but in both cases only for heating rates $<10{ }^{\circ} \mathrm{C} \min ^{-1}$. We were unable to isolate the two steps, and the entire first mass loss step has been treated as a single-step reaction in the kinetic analysis.

For the mass loss steps above $\sim 180{ }^{\circ} \mathrm{C}$, the MS measurements show strong signals from $\mathrm{m} / \mathrm{z} 52(\mathrm{CN})_{2}$ and $\mathrm{m} / \mathrm{z} 44\left(\mathrm{CO}_{2}\right)$. The mass gain at $\sim 220{ }^{\circ} \mathrm{C}$ is attributable to a backstroke effect at the beginning of a rapid exothermic combustion and is accompanied by a strong signal from $m / z, 44\left(\mathrm{CO}_{2}\right)$. Steps above $400{ }^{\circ} \mathrm{C}$ show also MS signals

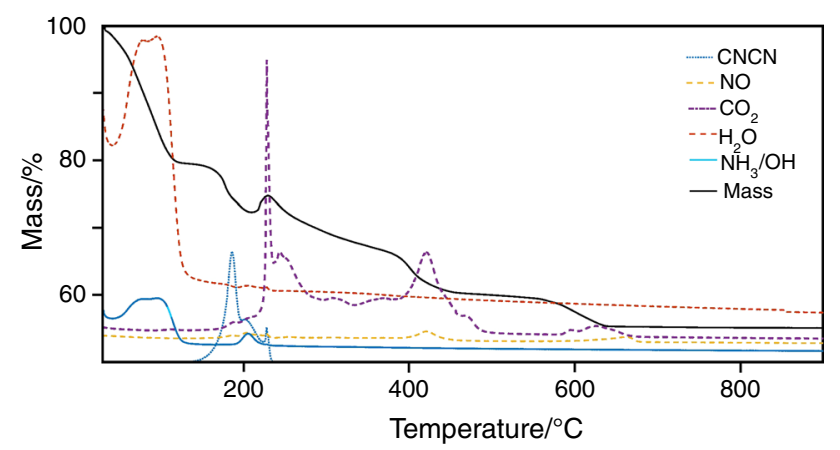

Fig. 3 TG-MS curves for thermal dehydration of $x=1.0$ in air at a heating rate of $10{ }^{\circ} \mathrm{C} \mathrm{min}^{-1}$ and a sample mass of $\sim 10 \mathrm{mg}$ from $\mathrm{NO}_{2}$ and NO. Similar thermal behaviours of decomposition of hexacyanoferrates in air have been reported in other studies [29].

The effect of varying sample amount on obtained TG curves is shown in Fig. 4. The dehydration step is consistently shifted to higher temperatures with increasing sample amount, and also when using a lidded crucible, while the mass loss of the step remains constant. Further decomposition steps are found to be strongly dependent on sample amount. Sample amounts of $\sim 10 \mathrm{mg}$ were used in all subsequent measurements, as a compromise for high resolution and high sensitivity.

TG curves for different $x$ and using both thermobalances are shown in Fig. 5. The curves were recorded in air and using a heating rate of $10{ }^{\circ} \mathrm{C} \min ^{-1}$. The dehydration steps for different $x$ are found to be similar for the two instruments. They are shifted slightly to the right for the JT, which may be attributed to the difference in sample containers used, pans for the DT and crucibles for the JT, and gas flow directions, horizontal for the DT and upwards for the JT. The decomposition steps at higher temperatures show larger differences in curves from the two thermobalances.

End products were characterized by heating samples in a tube furnace to $900{ }^{\circ} \mathrm{C}$ and keeping them there for $1 / 2 \mathrm{~h}$. In air, they were identified by X-ray powder diffraction to be oxides containing $\mathrm{Cu}^{2+}$ and predominantly $\mathrm{Fe}^{3+} ; \mathrm{CuO}$ (PDF 7-0518), $\mathrm{CuFe}_{2} \mathrm{O}_{4}$ (PDF 34-425) and a spinel phase isotypic with $\mathrm{Fe}_{3} \mathrm{O}_{4}$ (PDF 11-614). In $\mathrm{N}_{2}$ gas atmosphere, the identified phases were $\mathrm{Cu}$ (PDF 3-1005) and Fe (PDF 7-9753) metal, while no K-containing phase could be detected.

We find that the mass loss steps above $\sim 180{ }^{\circ} \mathrm{C}$ are difficult to analyse, as they depend on type of instrument, sample containers used, heating rate, and sample amount. They also show a complex variation with $x$.

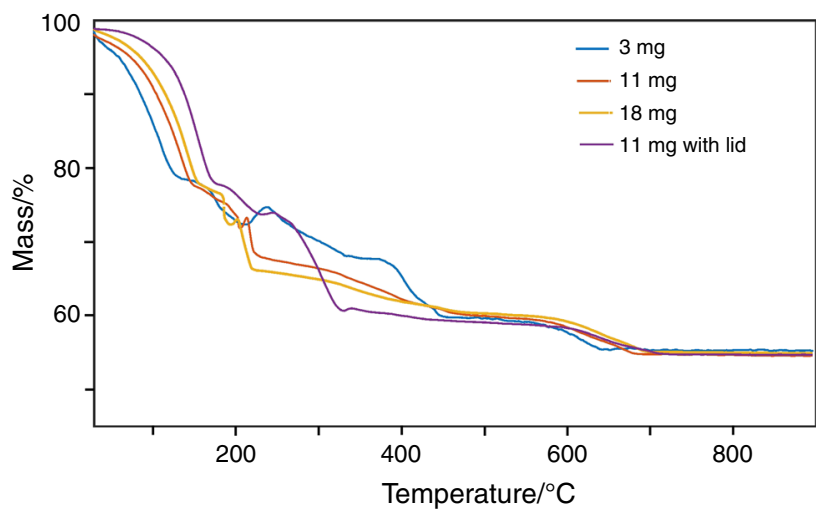

Fig. 4 TG curves for $x=1.0$ with varying sample amounts, and a curve with a lidded crucible used, recorded in air at a heating rate of $10{ }^{\circ} \mathrm{C} \min ^{-1}$ using the JT 

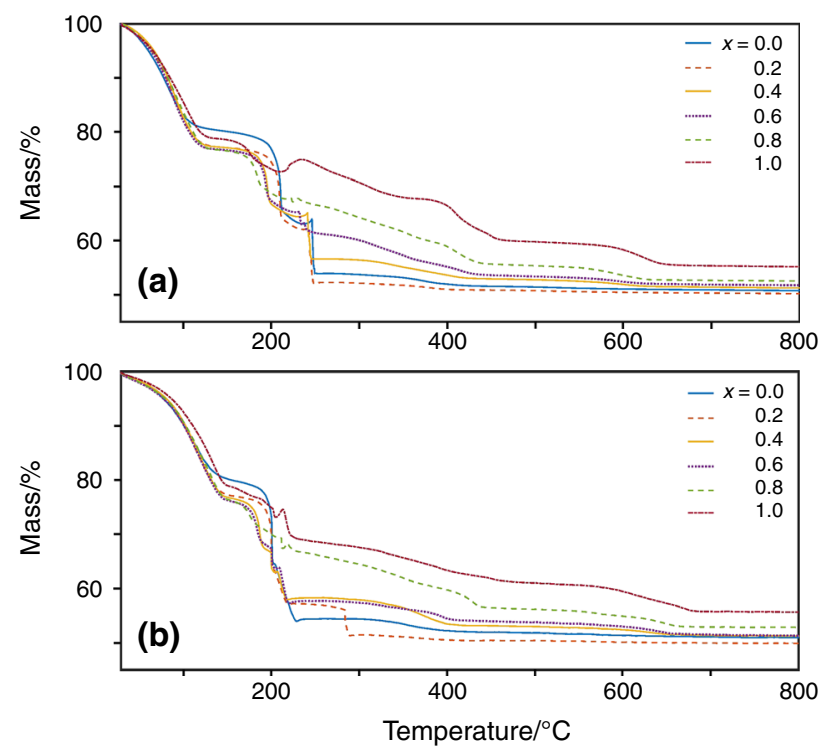

Fig. 5 TG curves for various $x$, recorded in air with a heating rate of $10{ }^{\circ} \mathrm{C} \min ^{-1}$, using a the DT and $\mathbf{b}$ the JT

\section{Degree of hydration}

Experiments, using the DT, in which samples were weighed in ambient atmosphere prior to the TG runs showed that there is a very fast initial water loss that occurs when the sample is subjected to the dry atmosphere in the thermobalance, see Fig. 6a. This initial mass loss, corresponding to $\sim 10 \%$ of the total water content, is too fast to be properly registered by any of the two thermobalances
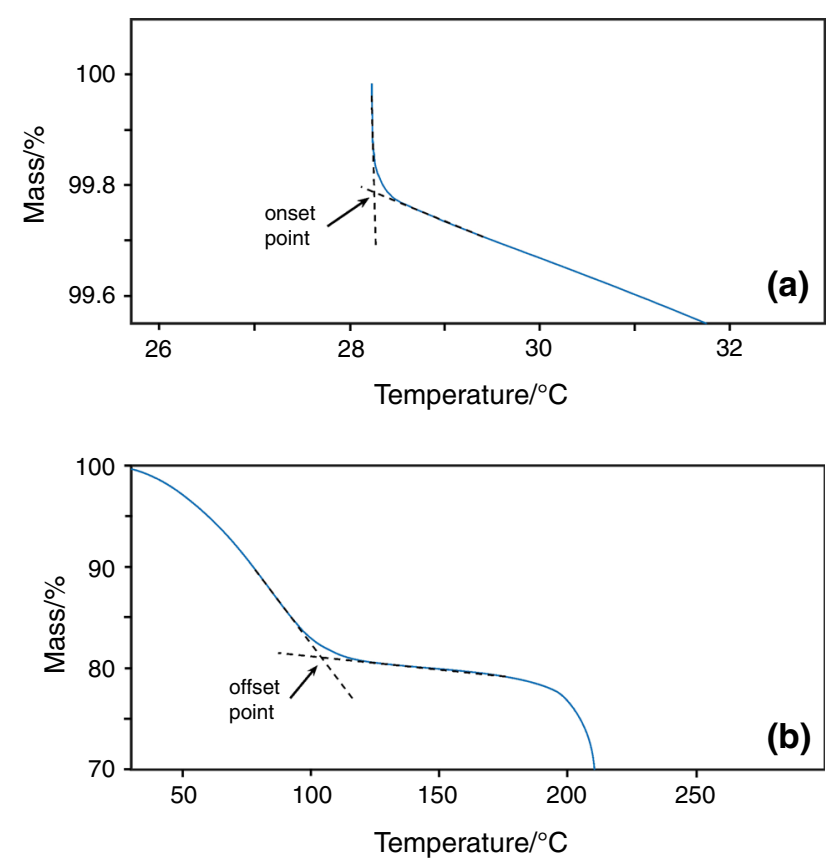

Fig. 6 Extrapolated a onset and $\mathbf{b}$ offset points defining the start and end of the dehydration used. Considering the small size of the grains, and as a consequence large surface area, of the samples, this water is likely to be surface adsorbed. As the exact starting point in the TG curves of the dehydration is ill-defined, this initial part of the TG curves was not included in the estimations of the degree of hydration and kinetic analysis. The start (onset) and end (offset) of the first reaction step were defined for all the TG curves as shown in Fig. 6.

The TG dehydration step was found to be reproducible and water contents, $n$, determined using the two thermobalances are in very good agreement, see Table 1 . The determined water content $n$ falls between 2.9 and 3.9 per formula unit. The expected ideal maximum $n$ is 4 or, if the presence of $\mathrm{K}$ in a cavity precludes an occupation of a water molecule in that cavity, $4-2 x / 3$, i.e. 3.33 for $x=1.0$. The water content is found to increase with increasing $x$ for $x \leq 0.8$, which is not what is expected and it is contrary to what has been reported in other studies, where alkali-rich compounds have been found to have lower water contents than alkali-free ones [13, 14]. The observed variation with $x$ can qualitatively be attributed to the fact that the incorporated $\mathrm{K}^{+}$ions benefits energetically by coordination to water. Accordingly, the water content will for lower $x$ increase with increasing $\mathrm{K}$ content, as $x$ increases, until a maximum content, dictated by the structure, is reached. For higher $x$ values, it may decrease because the incorporation of $\mathrm{K}$ decreases the available sites for water. The total water content, $n_{\mathrm{T}}$, including the water from the initial very fast mass loss, exceeds for some composition 4, a further indication of the presence of surface adsorbed water.

\section{DSC}

TG-DSC curves for $x=1.0$ are shown in Fig. 7. The endothermal dehydration up to $\sim 160{ }^{\circ} \mathrm{C}$ is followed at $\sim 200{ }^{\circ} \mathrm{C}$ by exothermal processes associated with first

Table 1 Determined water contents per formula unit $\mathrm{K}_{2 \mathrm{x} / 3} \mathrm{Cu}^{\text {II }}$ $\left[\mathrm{Fe}_{\mathrm{x}}^{\mathrm{II}} \mathrm{Fe}_{1-\mathrm{x}}^{\mathrm{III}}(\mathrm{CN})_{6}\right]_{2 / 3} \cdot n \mathrm{H}_{2} \mathrm{O} ; n=$ as determined by $\mathrm{TG}, n_{\mathrm{In}}=$ water content corresponding to the initial very fast mass loss, $n_{\mathrm{T}}=$ total water content $=n+n_{\text {In }}$

\begin{tabular}{llllll}
\hline$x$ & $n$ & & & DT & \\
\cline { 2 - 3 } \cline { 6 - 6 } & JT & DT & & $n_{\text {In }}$ & $n_{\text {T }}$ \\
\hline 0.0 & 2.90 & 2.89 & & 0.44 & 3.33 \\
0.2 & 3.43 & 3.42 & & 0.44 & 3.86 \\
0.4 & 3.57 & 3.50 & 0.48 & 3.98 \\
0.6 & 3.78 & 3.70 & & 0.34 & 4.04 \\
0.8 & 3.88 & 3.84 & & 0.44 & 4.28 \\
1.0 & 3.41 & 3.38 & & 0.45 & 3.83 \\
\hline
\end{tabular}




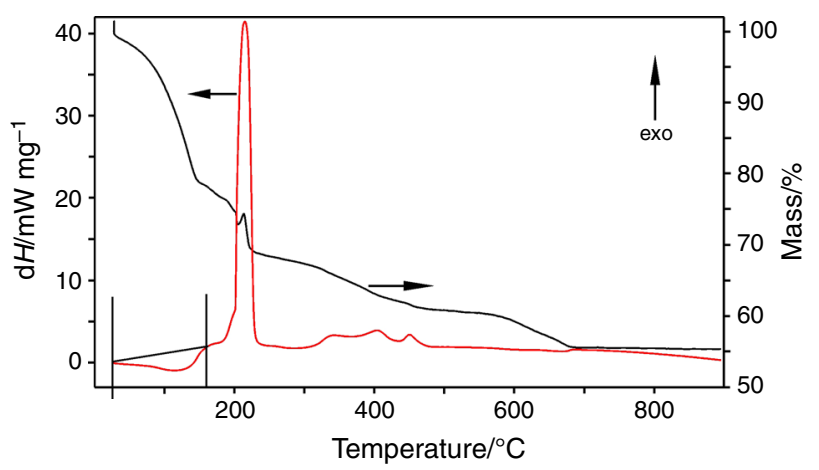

Fig. 7 TG-DSC curves for $x=1.0$ recorded in air at a heating rate of $10^{\circ} \mathrm{C} \mathrm{min}-1$, using the JT. The dehydration enthalpy was estimated by the area of the DSC peak between the beginning and $160{ }^{\circ} \mathrm{C}$ as illustrated

$(\mathrm{CN})_{2}$ and then $\mathrm{CO}_{2}$ leaving, cf. Figure 3, and at higher temperatures by further exothermal decomposition steps.

The dehydration enthalpy per mole of compound, $\Delta H_{\mathrm{m}}$, was estimated by the area of the DSC peak between the beginning and $160{ }^{\circ} \mathrm{C}$, as shown in Fig. 7. The obtained values are given in Table 2 , together with values per mole of water $n, \Delta H_{\mathrm{n}}$. The $\Delta H_{\mathrm{m}}$ values are believed to underestimate true values, since the dehydration starts immediately and shifts the registered apparent DSC starting zero level to lower values.

The $x$ dependencies of $\Delta H_{\mathrm{m}}$ and $\Delta H_{\mathrm{n}}$ are shown in Fig. 8. The variation of $\Delta H_{\mathrm{m}}$ with $x$ is similar to the variation of $n$, cf. Table 1 , while $\Delta H_{\mathrm{n}}$ increases from $52 \mathrm{~kJ} \mathrm{~mol}^{-1}$ for $x=0.0$ to $68 \mathrm{~kJ} \mathrm{~mol}^{-1}$ for $x=1.0$, i.e. by $\sim 30 \%$. The latter values are slightly higher than the evaporation enthalpy of water at $100{ }^{\circ} \mathrm{C}, 40.7 \mathrm{~kJ} \mathrm{~mol}^{-1}$ [30].

\section{Kinetic analysis}

\section{Estimation of the activation energy}

Model-free kinetic analysis requires at least three curves obtained at varying heating rates [22]. Four different heating rates were used here; $2,5,10$, and $20{ }^{\circ} \mathrm{C} \mathrm{min}^{-1}$.

Table 2 Determined dehydration enthalpies for $\mathrm{K}_{2 \mathrm{x} / 3} \mathrm{Cu}^{\mathrm{II}}\left[\mathrm{Fe}_{\mathrm{x}}^{\mathrm{II}-}\right.$ $\left.\mathrm{Fe}_{\text {III- }}(\mathrm{CN})_{6}\right]_{2 / 3} \cdot n \mathrm{H}_{2} \mathrm{O}$; (a) per formula unit, $\Delta H_{\mathrm{m}}$, and (b) per formula unit of determined water content $n, \Delta H_{\mathrm{n}}$

\begin{tabular}{lll}
\hline$x$ & $\Delta H_{\mathrm{m}} / \mathrm{kJ} \mathrm{mol}^{-1}$ & $\Delta H_{\mathrm{n}} / \mathrm{kJ} \mathrm{mol}^{-1}$ \\
\hline 0.0 & 151 & 52 \\
0.2 & 175 & 51 \\
0.4 & 194 & 55 \\
0.6 & 213 & 58 \\
0.8 & 236 & 62 \\
1.0 & 230 & 68 \\
\hline
\end{tabular}

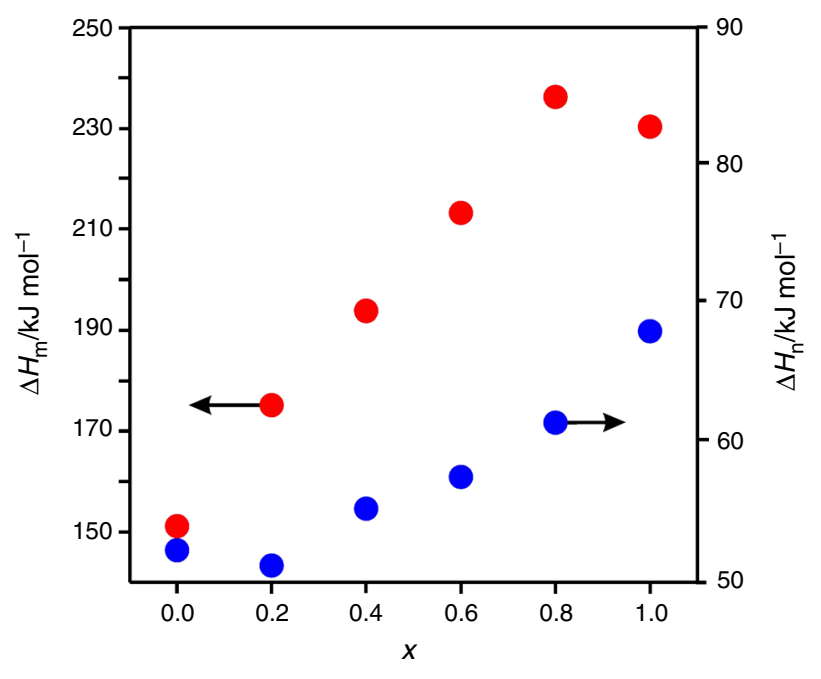

Fig. 8 The $x$ dependencies of $\Delta H_{\mathrm{m}}$ and $\Delta H_{\mathrm{n}}$

The TG water loss step for $x=1.0$ and different heating rates is shown in Fig. 9a and corresponding $\alpha$ curves in Fig. $9 b$.

The activation energies, $E_{\mathrm{a}}$, were estimated for $x=0.0$ and $x=1.0$ in the $\alpha$-range $0.2-0.8$, using data from both thermobalances and two model-free computational methods, KAS and Friedman. According to these isoconversional methods, the dependence of $\ln \left(\beta / T^{2}\right)$ and $\ln [\beta(\mathrm{d} \alpha /$ $\mathrm{d} t)$ ], respectively, was plotted against $1 / T$ for different values of $\alpha$, see Fig. 10. The effective values of $E_{\alpha}$, as a
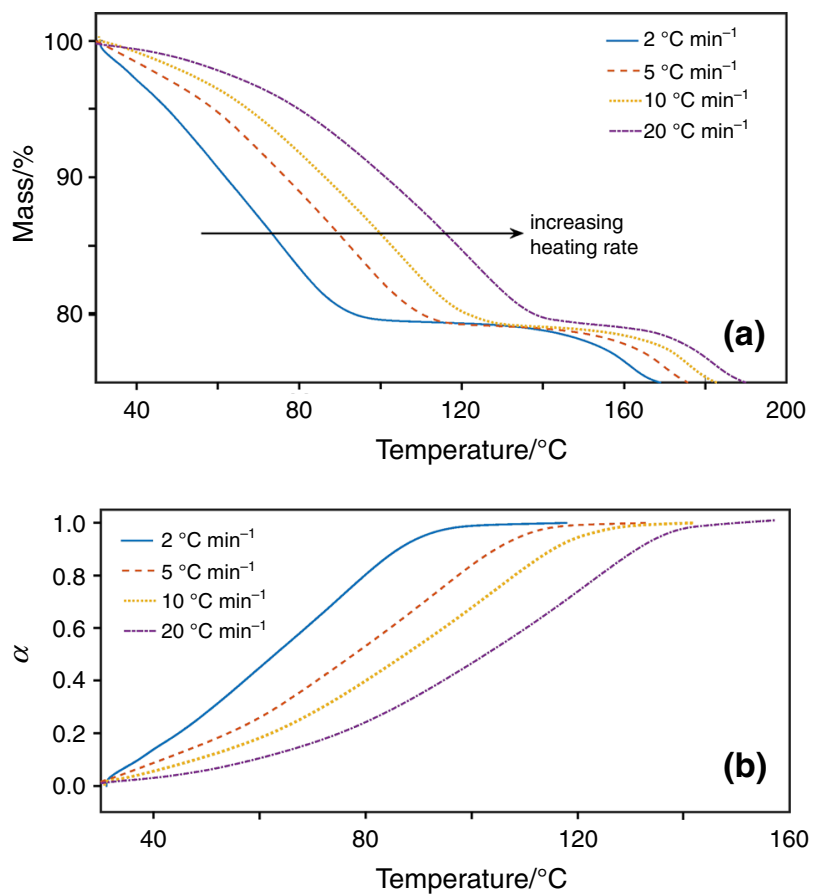

Fig. 9 a TG curves, recorded in air with the DT, for $x=1.0$ and different heating rates, and $\mathbf{b}$ corresponding $\alpha$ versus $T$ curves 

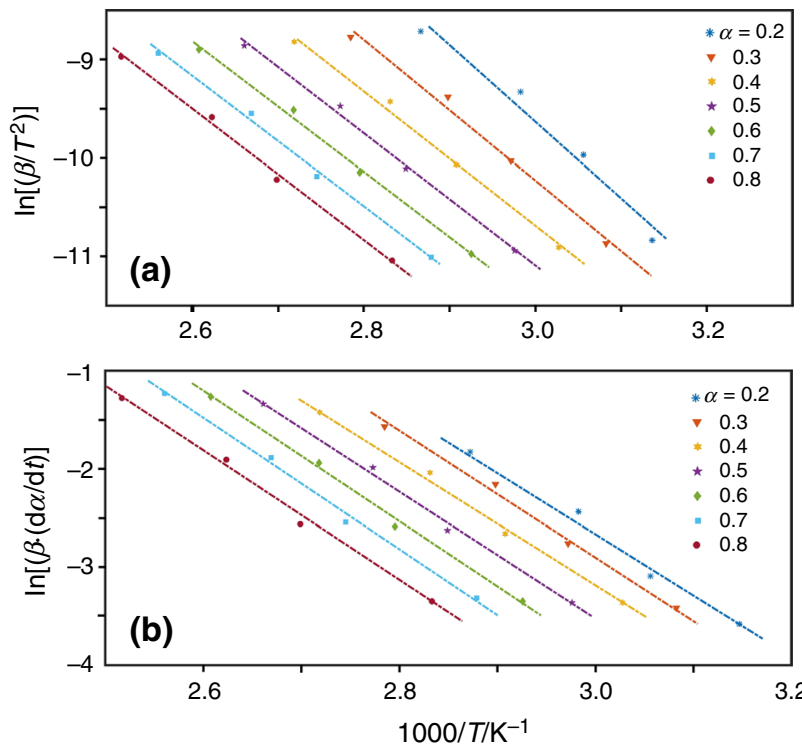

Fig. 10 Plots of a $\ln \left(\beta / T^{2}\right)$ (KAS method) and b $\ln [\beta(\mathrm{d} \alpha / \mathrm{d} t)]$ (Friedman method), for $x=1.0$ and measurements in air using the DT

function of $\alpha$, were determined from the slope, $-E_{\alpha} / R T$, of the straight lines by linear least-squares regression.

The values of determined activation energies are listed in Table 3, together with those determined from isothermal measurements using the DT (see Figs. S7 and S8). The $E_{\text {a }}$ values obtained using the different experimental and computational methods, as well as both thermobalances, are very similar, supporting their credibility.

The $E_{\mathrm{a}}$ values are found to be almost constant in the range $0.2 \leq \alpha \leq 0.8$, with the highest and lowest values deviating by $\sim 10 \%$ from the average value, implying that the dehydration is treatable as a single-step process [23]. The determined average values range between 51 and

Table 3 Activation energies $\left(\mathrm{kJ} \mathrm{mol}^{-1}\right)$ for the dehydration of $x=0.0$ and 1.0 from non-isothermal and isothermal TG measurements for $0.2 \leq \alpha \leq 0.8$

\begin{tabular}{lllll}
\hline Method & Instrument & $x$ & $E_{\mathrm{a}}$ & Average $E_{\mathrm{a}}^{\mathrm{a}}$ \\
\hline \multicolumn{2}{l}{ Non-isothermal } \\
Friedman & DT & 0.0 & $50.0-57.3$ & $54(7)$ \\
Friedman & JT & 0.0 & $47.6-54.8$ & $51(7)$ \\
Friedman & DT & 1.0 & $52.5-55.4$ & $54(3)$ \\
Friedman & JT & 1.0 & $56.0-62.4$ & $59(6)$ \\
KAS & DT & 0.0 & $52.9-63.8$ & $57(10)$ \\
KAS & JT & 0.0 & $54.1-62.3$ & $58(8)$ \\
KAS & DT & 1.0 & $52.9-63.8$ & $57(10)$ \\
KAS & JT & 1.0 & $55.0-63.6$ & $58(9)$ \\
Isothermal & & & & \\
Friedman & DT & 0.0 & $53.1-61.6$ & $56(9)$ \\
Friedman & DT & 1.0 & $49.4-64.4$ & $56(15)$ \\
\hline
\end{tabular}

${ }^{\mathrm{a}}$ The numbers in parenthesis are the spread in $E_{\mathrm{a}}$ for $0.2 \leq \alpha \leq 0.8$
$59 \mathrm{~kJ} \mathrm{~mol}^{-1}$, and no significant difference is observed between $x=0.0$ and $x=1.0$. The overall average is $56 \mathrm{~kJ} \mathrm{~mol}^{-1}$. It is of the same magnitude as those reported for dehydration of the PBAs zinc- and nickel-hexacyanocobaltate, 60 and $90 \mathrm{~kJ} \mathrm{~mol}^{-1}$, respectively, determined by using modulated TG [18].

Additional isothermal measurements for $x=0.0$ in nitrogen atmosphere yielded activation energies lower than those obtained in air, ranging between 30 and $40 \mathrm{~kJ} \mathrm{~mol}^{-1}$. Studies of the gas adsorption abilities of PBAs have shown that $\mathrm{CO}_{2}$ adsorption can reach $\sim 10$ mass $\%$, whereas little or no uptake of $\mathrm{N}_{2}$ has been reported [31, 32]. The higher activation energies in air might thus be due to an affinity for $\mathrm{CO}_{2}$ in air that introduces a steric hindrance for the migration of the water molecules.

\section{Evaluation of pre-exponential factor $A$ and reaction model} $g(\alpha)$

Values of $E_{\mathrm{j}}$ and $\ln A_{\mathrm{j}}$ were evaluated by fitting seven deceleratory reaction models, listed in Table 4 , to the experimental data, for $\alpha$ between 0.2 and 0.8 , according to Eq. (4). The compensation effect constants, $c$ and d, were evaluated from plots of $\ln A_{\mathrm{j}}$ versus $E_{\mathrm{j}}$, see Fig. 11 . The model-free values of $\ln A_{\alpha}$ were then computed at different conversion degrees as described by the linear Eq. (10) by inserting the corresponding $E_{\alpha}$ values. The $\ln A_{\alpha}$ values were found to vary in the range of $10.2-13.6 \mathrm{~s}^{-1}$, with an average of $11.4 \mathrm{~s}^{-1}$, and showed no significant difference between different heating rates.

The observed independence of the activation energy with conversion shows that the dehydration process, for both $x=0.0$ and $x=1.0$, is treatable as a single-step reaction. In Fig. 12, the integral form of the reaction model, $g(\alpha)$, has been reconstructed numerically, for $x=1.0$ and a heating rate of $10{ }^{\circ} \mathrm{C} \mathrm{min}{ }^{-1}$, and compared to theoretical $g(\alpha)$ curves for different models. The experimental (dotted) curve best fits the three-dimensional diffusion D3 Jander model. A detailed theoretical description of this model can be found in the literature [21].

Table 4 Reaction models fitted to experimental data according to Eq. (8)

\begin{tabular}{ll}
\hline Reaction model & $g(\alpha)$ \\
\hline F1 & $-\ln (1-\alpha)$ \\
D1 & $\alpha^{2}$ \\
D2 & {$[(1-\alpha) \ln (1-\alpha)]+\alpha$} \\
D3 & {$\left[1-(1-\alpha)^{1 / 3}\right]^{2}$} \\
D4 & $1-(2 \alpha / 3)-(1-\alpha)^{2 / 3}$ \\
P2 & $\alpha^{1 / 2}$ \\
R2 & {$\left[1-(1-\alpha)^{1 / 2}\right]$} \\
\hline
\end{tabular}




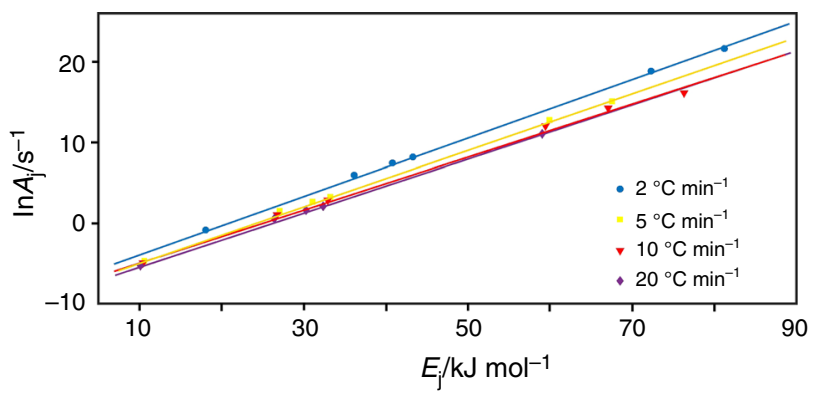

Fig. $11 \ln \left(A_{\mathrm{j}}\right)$ plotted versus $E_{\mathrm{j}}$ for $x=1.0$ and different reaction models $j$

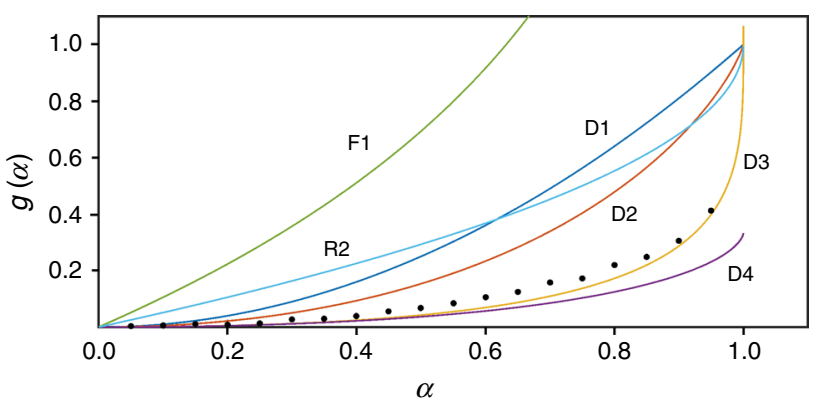

Fig. 12 Numerical reconstruction of $g(\alpha)$ versus $\alpha$ for $x=1.0$ and a heating rate of $10{ }^{\circ} \mathrm{C} \mathrm{min}{ }^{-1}$ (dotted line), together with corresponding curves for different deceleratory models

It can be added that a direct model fitting was also applied to this set of data, but the most probable reaction model could thereby not be distinguished.

\section{Isothermal predictions}

Predictions under isothermal conditions were made by inserting the kinetic triplet, solved for from non-isothermal data, into Eq. (12). A comparison with experimental isothermal curves at four different temperatures between 50 and $110^{\circ} \mathrm{C}$ is shown in Fig. 13. The simulated and experimental curves are in decent agreement and overlap at parts.

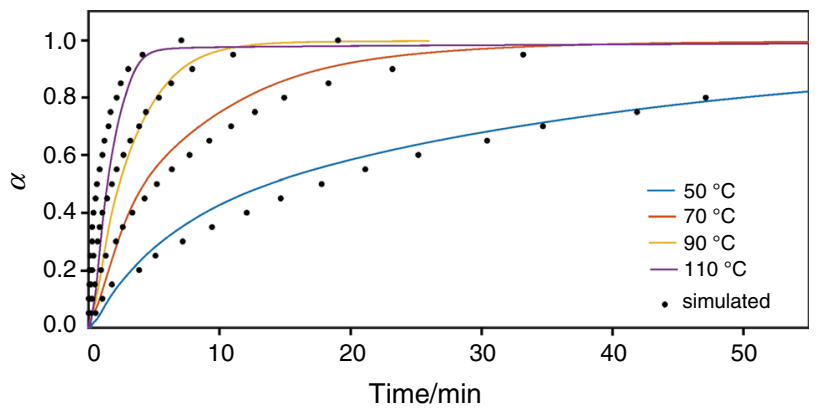

Fig. 13 Simulated (dotted) and experimental curves for isothermal measurements for $x=1.0$
Determination of diffusion constant from isothermal TG data

For diffusion out from spherical particles with radius $r$, the diffusion constant, $D_{\mathrm{T}}$, at different $T$ can be estimated by fitting $\alpha$ from isothermal data to the equation [33]

$\alpha=1-\frac{6}{\pi^{2}} \sum_{n=1}^{\infty} \frac{1}{n^{2}} \cdot \exp \left(-n^{2} \pi^{2} D_{\mathrm{T}} t / r^{2}\right)$

It is thereby assumed that $D_{\mathrm{T}}$ is independent of water content. For the present data, good fits for $x=1.0$ were obtained for $T \leq \sim 90{ }^{\circ} \mathrm{C}$, see Fig. S10. For $x=0.0$, reasonably good fits were only obtained for $T \leq \sim 50{ }^{\circ} \mathrm{C}$. The poorer fits for higher $T$ are attributable to the fact that the water loss is then too fast relative to the time it takes for the DT to reach a stable $T$, i.e. most water is lost at a nonconstant $T$. For $x=1.0$, the activation energy for $D_{\mathrm{T}} / r^{2}$ was obtained from an Arrhenius plot to be 55 (2) $\mathrm{kJ} \mathrm{mol}^{-1}$, which is as expected in good agreement with the overall average value of $56 \mathrm{~kJ} \mathrm{~mol}^{-1}$ from the model-free analyses. Using a value of $25 \mathrm{~nm}$ as an effective $r$ yielded estimated diffusion constants of $6 \times 10^{-17} \mathrm{~cm}^{2} \mathrm{~s}^{-1}$ at $25{ }^{\circ} \mathrm{C}$ and $5 \times 10^{-15} \mathrm{~cm}^{2} \mathrm{~s}^{-1}$ at $100{ }^{\circ} \mathrm{C}$. These values are considerably lower than those for common zeolites $[34,35]$, for which the diffusion constants are more comparable with that in pure water, $\sim 2 \times 10^{-5} \mathrm{~cm}^{2} \mathrm{~s}^{-1}$ $[36,37]$.

\section{Conclusions}

The thermal decomposition of CuHCF is found to be similar to that of other PBAs in terms of dehydration temperature and evolved gases. The water content is estimated to 2.9-3.9 molecules of water $n$ per formula unit $\mathrm{K}_{2 \mathrm{x} / 3} \mathrm{Cu}^{\mathrm{II}}\left[\mathrm{Fe}_{\mathrm{x}}^{\mathrm{II}} \mathrm{Fe}_{1-\mathrm{x}}^{\mathrm{III}}(\mathrm{CN})_{6}\right]_{2 / 3} \cdot n \mathrm{H}_{2} \mathrm{O}$, with an additional $\sim 10 \%$ of water, presumably surface adsorbed, that leave very fast when samples become exposed to a dry atmosphere. The whole water is found to leave in the first mass loss step up to $\sim 130^{\circ} \mathrm{C}$, contrary to what has been reported for PB [38, 39]. All data, except for $x=1.0$, accord with a single-step process with a constant activation energy. This implies that the release of zeolitic and coordinated water is energetically very similar. For $x=1.0$, TG-MS and $\mathrm{d} \alpha /$ $\mathrm{d} t$ curves show that the dehydration takes place by two close overlapping processes. However, it was treated for all $x$, including $x=1.0$, as a single-step process in the kinetic analysis and the obtained kinetic parameters describe the reaction adequately as such. The dehydration was found to be diffusion controlled, following the D3 Jander model, and independent of $x$, with an activation energy of $\sim 56 \mathrm{~kJ} \mathrm{~mol}^{-1}$ at conversion degrees $0.2 \leq \alpha \leq 0.8$. 
Per mole of water, the dehydration enthalpy $\Delta H_{\mathrm{n}}$ increases from $52 \mathrm{~kJ}\left(\mathrm{~mol} \mathrm{H}_{2} \mathrm{O}\right)^{-1}$ for $x=0.0$ to $68 \mathrm{~kJ}$ $\left(\mathrm{mol} \mathrm{H}_{2} \mathrm{O}\right)^{-1}$ for $x=1.0$. These values can be compared with the enthalpy of vaporization of water at $100{ }^{\circ} \mathrm{C}$, $40.7 \mathrm{~kJ} \mathrm{~mol}^{-1}$ [30]. The dehydration enthalpy is thus $11 \mathrm{~kJ}$ $\left(\mathrm{mol} \mathrm{H} \mathrm{H}_{2} \mathrm{O}\right)^{-1}$ for $x=0.0$ and $27 \mathrm{~kJ}\left(\mathrm{~mol} \mathrm{H}_{2} \mathrm{O}\right)^{-1}$ for $x=1.0$ higher than that of pure water. These low values imply that the interaction of the water with the crystal structure framework is moderate. The significant increase with $x$ implies also that this interaction increases with $\mathrm{K}$ content, which can be explained by the $\mathrm{H}_{2} \mathrm{O}$ molecules forming bonds to the incorporated $\mathrm{K}^{+}$ions.

Prado and Vyazovkin have used DSC to study dehydration kinetics of wet samples of laponite, sodium montmorillonite and chitosan, for which they determined the average activation energies to be 47.90 (4), 52.6 (9), and 56.2 (2) $\mathrm{kJ} \mathrm{mol}^{-1}$, respectively. They also determined the corresponding dehydration enthalpies to be 54 (7), 57 (9), and $62(5) \mathrm{kJ}\left(\mathrm{mol} \mathrm{H}_{2} \mathrm{O}\right)^{-1}$ [40]. The activation energies were thus found to be slightly smaller but of comparable magnitude to the dehydration enthalpies. Similar activation energies have also been determined for dehydration of mixite, 54 (4) $\mathrm{kJ} \mathrm{mol}^{-1}$ [41], and a zeolite, $\sim 60 \mathrm{~kJ} \mathrm{~mol}^{-1}$ [42]. Our values comply well with these data. In this study, the derived activation energy of $\sim 56 \mathrm{~kJ} \mathrm{~mol}^{-1}$ is quite similar to the determined enthalpies of 52-68 kJ $\left(\mathrm{mol} \mathrm{H}_{2-}\right.$ $\mathrm{O})^{-1}$. For low $x$ values, the activation energy is found to be slightly larger than the determined enthalpies, but as already mentioned, the latter are likely to be underestimated due to the difficulty to define starting points for the DSC peaks.

Prado and Vyazovkin conclude in their study that the activation energy of dehydration should be larger than that of vaporization of water, which in turn should be similar to the evaporation enthalpy of water, except for dehydrations that are diffusion limited. For these, the activation energy is expected to be at least half as small as the dehydration enthalpy. The authors provide a list of activation energies for diffusion of water in various materials, similar to those they studied, ranging from 11 to $21 \mathrm{~kJ} \mathrm{~mol}^{-1}$ [40]. One may interpret this to imply that the dehydration of $\mathrm{CuHCF}$ is not diffusion limited, despite the kinetic analysis showing that it is best described by the D3 Jander model. Furthermore, the dynamics of water in PB has been studied by quasielastic neutron scattering by Sharma et al. [43] They determined the activation energy for diffusion to be $\sim 7 \mathrm{~kJ} \mathrm{~mol}^{-1}$ and the diffusion constant as $1.36 \times 10^{-5} \mathrm{~cm}^{2} \mathrm{~s}^{-1}$ at $300 \mathrm{~K}$. We are not able to give a satisfactory explanation for the discrepancy between their and our values, except by stating the obvious, that the removal of all water could be limited by movement along energetically unfavourable pathways.
Acknowledgements We thank Swedish Research Council VR for funding for Project: 2011-6512.

Open Access This article is distributed under the terms of the Creative Commons Attribution 4.0 International License (http://crea tivecommons.org/licenses/by/4.0/), which permits unrestricted use, distribution, and reproduction in any medium, provided you give appropriate credit to the original author(s) and the source, provide a link to the Creative Commons license, and indicate if changes were made.

\section{References}

1. Yang Z, Zhang J, Kintner-Meyer MCW, Lu X, Choi D, Lemmon JP, Liu J. Electrochemical energy storage for green grid. Chem Rev. 2011;111:3577-613.

2. Pasta M, Wessells CD, Liu N, Nelson J, McDowell MT, Huggins RA, Toney MF, Cui Y. Full open-framework batteries for stationary energy storage. Nat Commun. 2014;5:3007.

3. Kaye SS, Long JR. The role of vacancies in the hydrogen storage properties of Prussian blue analogues. Catal Today. 2007;120(3-4):311-6.

4. de Lara González GL, Kahlert H, Scholz F. Catalytic reduction of hydrogen peroxide at metal hexacyanoferrate composite electrodes and applications in enzymatic analysis. Electrochim Acta. 2007;52(5):1968-74.

5. Neff VD. Some performance characteristics of a Prussian blue battery. J Electrochem Soc. 1985;132(6):1382-4.

6. Keggin JF, Miles FD. Structures and formulae of Prussian blues and related compounds. Nature. 1936;137:577-8.

7. Buser HJ, Ludi A. Single-crystal study of Prussian blue: $\mathrm{Fe}_{4}[-$ $\left.\mathrm{Fe}(\mathrm{CN})_{6}\right]_{2} \cdot 14 \mathrm{H}_{2} \mathrm{O}$. Chem Soc Chem Commun. 1972;23:1299.

8. Herren F, Fischer P, Ludi A, Halg W. Neutron diffraction study of Prussian blue, $\mathrm{Fe}_{4}\left[\mathrm{Fe}(\mathrm{CN})_{6}\right]_{3} \cdot x \mathrm{H}_{2} \mathrm{O}$. Location of water molecules and long-range magnetic order. Inorg Chem. 1980;19(4):956-9.

9. Beall GW, Milligan WO, Korp J, Bernal I. Crystal structure of $\mathrm{Mn}_{3}\left[\mathrm{Co}(\mathrm{CN})_{6}\right]_{2} \cdot 12 \mathrm{H}_{2} \mathrm{O}$ and $\mathrm{Cd}_{3}\left[\mathrm{Co}(\mathrm{CN})_{6}\right]_{2} \cdot 12 \mathrm{H}_{2} \mathrm{O}$ by neutron and X-ray diffraction. Inorg Chem. 1977;16(11):2715-8.

10. Wilde RE, Ghosh NS, Marshall BJ. The Prussian blues. Inorg Chem. 1970;9(11):2512-6.

11. Bleuzen A, Escax V, Ferrier A, Villain F, Verdaguer M, Münsch $\mathrm{P}$, Itié J-P. Thermally induced electron transfer in a $\mathrm{CsCoFe}$ Prussian blue derivative: the specific role of the alkali-metal ion. Angew Chem Int Ed. 2004;43:3728-31.

12. Erickson N, Elliott N. Magnetic susceptibility and Mössbauer spectrum of $\mathrm{NH}_{4} \mathrm{Fe}^{3+} \mathrm{Fe}^{\mathrm{II}}(\mathrm{CN})_{6}$. J Phys Chem Solids. 1970;31:1195-7.

13. Ware M. Prussian blue: artists' pigment and chemists' sponge. J Chem Educ. 2008;85(5):612-21.

14. Buser H, Schwarzenbach D, Petter W, Ludi A. The crystal structure of Prussian blue : $\mathrm{Fe}_{4}\left[\mathrm{Fe}(\mathrm{CN})_{6}\right]_{3} \cdot x \mathrm{H}_{2} \mathrm{O}$. Inorg Chem. 1977;16(11):2704-10.

15. Ng CW, Ding J, Gan LM. Structure and magnetic properties of Zn-Fe cyanide. J Phys D Appl Phys. 2001;34(8):1188-92.

16. Rodríguez-Hernández J, Reguera E, Lima E, Balmaseda J, Martínez-García R, Yee-Madeira H. An atypical coordination in hexacyanometallates: structure and properties of hexagonal zinc phases. J Phys Chem Solids. 2007;68(9):1630-42.

17. Verdaguer M, Girolami GS. Magnetic Prussian blue analogs. In: Miller JS, Drillon M, editors. Magnetism, molecules to materials V. New York: Wiley-VCH; 2004. p. 283-346. 
18. Reyes-martínez O, Velázquez-Ortega JL. Synthesis of nanostructured materials for storing hydrogen as an alternative source to fossil fuel derivatives. In: Vivek Patel, editor. Advances in petrochemical. InTech; 2015. pp. 44-65. doi:10.5772/61076.

19. Ojwang DO, Grins J, Wardecki D, Valvo M, Renman V, Häggström L, Ericsson T, Gustafsson T, Mahmoud A, Hermann RP, Svensson G. Structure characterization and properties of K-containing copper hexacyanoferrate. Inorg Chem. 2016;55:5924-34.

20. Vyazovkin S, Wight CA. Kinetics in solids. Annu Rev Phys Chem. 1997;48:125-49.

21. Khawam A, Flanagan DR. Solid-state kinetic models : basics and mathematical fundamentals. Phys Chem B. 2006;110:17315-28.

22. Vyazovkin S, Burnham AK, Criado JM, Pérez-Maqueda LA, Popescu C, Sbirrazzuoli N. ICTAC Kinetics Committee recommendations for performing kinetic computations on thermal analysis data. Thermochim Acta. 2011;520:1-19.

23. Vyazovkin S, Wight CA. Isothermal and non-isothermal kinetics of thermally stimulated reactions of solids. Int Rev Phys Chem. 1998;17(3):407-33.

24. Friedman HL. Kinetics of thermal degradation of char-forming plastics from thermogravimetry. Application to a phenolic plastic. J Polym Sci Part C. 1964;6(1):183-95.

25. Coats AW, Redfern JP. Kinetic parameters from thermogravimetric data. Nature. 1964;201:68-9.

26. Kissinger HE. Reaction kinetics in differential thermal analysis. Anal Chem. 1957;29(11):1702-6.

27. Akahira T, Sunose T. Trans. joint convention of four electrical institutes, Paper No. 246, 1969 Research report, Chiba Institute of Technology. Sci Technol. 1971;16:22-31.

28. Vyazovkin SV, Lesnikovich AI. Estimation of the pre-exponential factor in the isoconversional calculation of effective kinetic parameters. Thermochim Acta. 1988;128:297-300.

29. De Marco D, Marchese A, Migliardo P, Bellomo A. Thermal analysis of some cyano compounds. J Therm Anal. 1987;32(3): 927-37.

30. Lide DR. CRC handbook of chemistry and physics. 83rd ed. New York: CRC Press; 2002.

31. Karadas F, El-Faki H, Deniz E, Yavuz CT, Aparicio S, Atilhan M. $\mathrm{CO}_{2}$ adsorption studies on Prussian blue analogues. Microporous Mesoporous Mater. 2012;162:91-7.
32. Motkuri RK, Thallapally PK, McGrail BP, Ghorishi SB. Dehydrated Prussian blues for $\mathrm{CO}_{2}$ storage and separation applications. Cryst Eng Commun. 2010;12(12):3965-4446.

33. Kärger J, Vasenkov S, Auerbach SM. Handbook of zeolite science and technology: diffusion in zeolites. In: Auerbach SM, Carrado KA, Dutta PK, editors. Diffusion in zeolites. New York: Marcel Dekker Inc.; 2003.

34. Sircar S, Myers A. chapter 22. In: Auerbach SM, Carrado KA, Dutta PK, editors. Handbook of zeolite science and technology: gas separation by zeolites. New York: Marcel Dekker Inc; 2003.

35. Jolic H, Méthivier A. Oil and gas science technology. Rev ICP. 2005;60:815-30.

36. Krynicki K, Green CD, Sawyer DW. Pressure and temperature dependence of self-diffusion in water. Faraday Discuss Chem Soc. 1978;66:199-208.

37. Parravano C, Baldeschwieler JD, Boudart M. Diffusion of water in zeolites. Science. 1967;155:1535-6.

38. Bal B, Ganguli S, Bhattacharya M. Bonding of water molecules in Prussian blue. A differential thermal analysis and nuclear magnetic resonance study. J Phys Chem. 1984;88:4575-7.

39. Ganguli S, Bhattacharya M. Studies of different hydrated forms of Prussian blue. J Chem Soc Faraday Trans 1. 1983;79(7): 1513-22.

40. Prado JR, Vyazovkin S. Activation energies of water vaporization from the bulk and from laponite, montmorillonite, and chitosan powders. Thermochim Acta. 2011;524(1-2):197-201.

41. Miletich R, Zemann J, Nowak M. Reversible hydration in synthetic mixite, $\mathrm{BiCu}_{6}(\mathrm{OH})_{6}\left(\mathrm{AsO}_{4}\right)_{3} \cdot \mathrm{nH}_{2} \mathrm{O} \quad(\mathrm{n} \leq 3)$ : hydration kinetics and crystal chemistry. Phys Chem Miner. 1997;24(6): 411-22.

42. Majchrzak-Kucęba I, Nowak W. Application of model-free kinetics to the study of dehydration of fly ash-based zeolite. Thermochim Acta. 2004;413(1-2):23-9.

43. Sharma VK, Mitra S, Kumar A, Yusuf SM, Juranyi F, Mukhopadhyay R. Diffusion of water in molecular magnet $\mathrm{Cu}_{0.75} \mathrm{Mn}_{0.75}\left[\mathrm{Fe}(\mathrm{CN})_{6}\right] \cdot 7 \mathrm{H}_{2} \mathrm{O}$. J Phys Condens Matter. 2011; 23(44):446002-9. 